\title{
Efficacy of Prophylactic Mesh in End-Colostomy Construction: A Systematic Review and Meta-analysis of Randomized Controlled Trials
}

\author{
Shuanhu Wang ${ }^{1} \cdot$ Wenbin Wang ${ }^{2} \cdot$ Bing Zhu $^{1} \cdot$ Guolei Song $^{1} \cdot$ Congqiao Jiang $^{1}$
}

Published online: 23 May 2016

(C) The Author(s) 2016. This article is published with open access at Springerlink.com

\begin{abstract}
Background Parastomal hernia is a very common complication after colostomy, especially end-colostomy. It is unclear whether prophylactic placement of mesh at the time of stoma formation could prevent parastomal hernia formation after surgery for rectal cancer. A systematic review and meta-analysis were conducted to evaluate the efficacy of prophylactic mesh in end-colostomy construction.

Methods PubMed, Embase, and the Cochrane Library were searched, covering records entered from their inception to September 2015. Randomized controlled trials (RCTs) comparing stoma with mesh to stoma without mesh after surgery for rectal cancer were included. The primary outcome was the incidence of parastomal hernia. Pooled risk ratios (RR) with $95 \%$ confidence intervals (CI) were obtained using random effects models.

Results Six RCTs containing 309 patients were included. Parastomal hernia occurred in $24.4 \%$ (38 of 156) of patients with mesh and $50.3 \%$ (77 of 153) of patients without mesh. Meta-analysis showed a lower incidence of parastomal hernia (RR, 0.42; $95 \%$ CI 0.22-0.82) and reoperation related to parastomal hernia (RR, 0.23; $95 \%$ CI $0.06-0.89)$ in patients with mesh. Stoma-related morbidity was similar between mesh group and non-mesh group (RR, 0.65; $95 \%$ CI 0.33-1.30).

Conclusions Prophylactic placement of a mesh at the time of a stoma formation seems to be associated with a significant reduction in the incidence of parastomal hernia and reoperation related to parastomal hernia after surgery for rectal cancer, but not the rate of stoma-related morbidity. However, the results should be interpreted with caution because of the heterogeneity among the studies.
\end{abstract}

\section{Introduction}

Colorectal cancer is the third most common malignancy worldwide, but its mortality is considerably lower than that of other cancers [1]. Although surgical techniques and instruments have been greatly improved, many patients

Shuanhu Wang

knight01030103@126.com

1 Department of Gastrointestinal Surgery, The First Affiliated Hospital of Bengbu Medical College, Bengbu, Anhui, China

2 Department of General Surgery, The Fourth Affiliated Hospital of Anhui Medical University, Hefei, Anhui, China with rectal cancer still suffer permanent colon stoma. Parastomal hernia is a common complication of endcolostomy. The incidence of parastomal hernia varies from 16 to $57 \%$ [2, 3]. Because patients with rectal cancer usually survive for long periods, the incidence of the parastomal hernia may be even higher than reported.

Parastomal hernia can not only significantly reduce patients' quality of life, but also cause a variety of specific complications such as pain, bleeding, bowel obstruction, and bowel strangulation [4, 5]. Although not all cases of parastomal hernia require surgical repair, there are a variety of surgical techniques. Local fascial repair, relocation of the stoma, and local repair of the parietal defect using 
meshes are the three basic methods of repair. The surgical approach may be open or laparoscopic. The treatment results were disappointing due to the $16-52 \%$ recurrence rate and about 14-23\% other complications [6-9].

Because of the unsatisfactory results of existing treatments, it has been proposed that the best solution is to prevent parastomal hernia at the time of stoma formation. Some studies have found that prophylactic placement of mesh was associated with a significant reduction the occurrence of parastomal hernia without increasing morbidity [10], but this association was not found in other studies [11]. For this reason, a systematic review and metaanalysis of randomized controlled trials was performed to determine the efficacy and safety of prophylactic mesh in patients with rectal cancer after end-colostomy.

\section{Materials and methods}

This systematic review and meta-analysis was conducted in accordance with Preferred Reporting Items for Systematic Reviews and Meta-analyses (PRISMA) [12].

\section{Literature search and inclusion criteria}

Two authors (S.W. and B.Z.) independently searched electronic databases (inception to September 2015) including PubMed, Embase, and the Cochrane Library. Search terms included "rectal neoplasms," "rectal cancer," "colostomy," "surgical mesh," and "parastomal hernia," and were searched in titles and abstracts. Free text searches and MeSH searches were performed. The search had no language restrictions. References of the articles included were also read to identify related articles.

Studies that met the following criteria were included: (1) population: patients receiving permanent end-colostomy surgery (Miles or Hartmann operation) to treat cancer of the rectum; (2) intervention: mesh insertion at the time of formation of end-colostomy; (3) comparison: no mesh insertion at the time of formation of end-colostomy; (4) outcome measure: the incidence of parastomal hernia; (5) study design: RCT.

\section{Data extraction, outcome measures, and assessment of risk of bias}

Two authors independently extracted the data (S.W. and W.W.), and discrepancies were resolved through discussion. When no consensus could be reached, a third specialist was consulted (C.J.). The following information was extracted from each selected study: first author, year of publication, publishing country, published journal, type of mesh, position of mesh placement, location of stoma, and diagnostic bases of parastomal hernia. The primary outcome was the incidence of parastomal hernia. Secondary outcomes included stoma-related morbidity and reoperation related to parastomal hernia. Parastomal hernia was defined clinically and radiologically by a CT scan performed to identify possible subclinical parastomal hernia [13].

Assessment for risk of bias was conducted in accordance with the Cochrane handbook for systematic reviews of interventions (version 5.1.0) by two authors (S.W. and G.S.) [14]. Risk of bias was judged as "low risk," "unclear risk," and "high risk" according to the following domains: random sequence generation, allocation concealment, blinding of participants and personnel, blinding of outcome assessment, incomplete outcome data, selective reporting, and other bias.

The overall quality of the evidence for each outcome was evaluated using the Grading of Recommendations Assessment, Development and Evaluation (GRADE) approach [15]. GRADE Working Group grades of evidence were as follows: high quality: further research is very unlikely to change our confidence in the estimate of effect; moderate quality: further research is likely to have an important impact on our confidence in the estimate of effect and may change the estimate; low quality: further research is very likely to have an important impact on our confidence in the estimate of effect and is likely to change the estimate; and very low quality: any estimate of effect is very uncertain.

\section{Statistical analysis}

Pooled RR and $95 \%$ CI were estimated for each outcome. Statistical heterogeneity was assessed using $\chi^{2}$ and $I^{2}$ statistics. Heterogeneity was considered significant if the $P$ value $\left(\chi^{2}\right)$ was $<0.1$ and $I^{2}$ was $>50 \%$. A random effects model was used regardless of heterogeneity. Whenever significant heterogeneity was present, possible sources of heterogeneity were assessed. For instance, a sensitivity analysis was performed and the study was excluded if the results were outside the range established by the others. Subgroup analysis was also performed, and the subgroups were based on the position of mesh placement (sublay vs. IPOM). The effects of treatment in different subgroups were compared using tests for interaction. The $P$ value $<0.05$ supports a different treatment effect in the tested subgroups [16]. Potential publication bias was assessed by a visual inspection of the Begg's funnel plots where the log RR was plotted against their standard errors. The Begg's test was used to measure the potential presence of publication bias [17]. Statistical analysis was performed with Stata 12.0 (Stata Corporation, College Station, TX, USA) and RevMan 5.3 (Nordic Cochrane Centre, Cochrane Collaboration, Copenhagen, Denmark). 


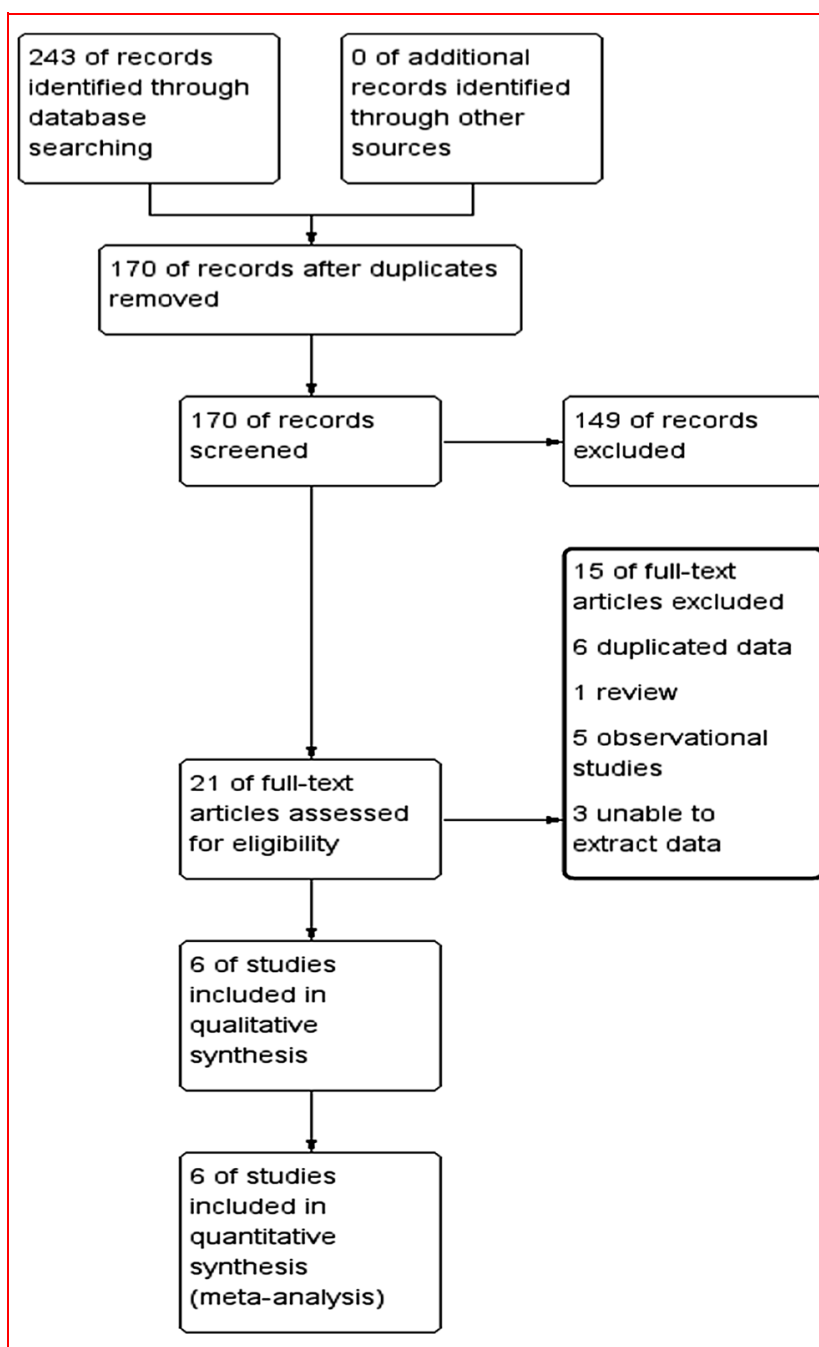

Fig. 1 Flow chart of study screening and selection

\section{Results}

\section{Search results and study characteristics}

The initial search identified 243 studies. After removal of 73 duplicate studies, 170 articles remained. After reading of the titles and abstracts, 149 studies were excluded due to irrelevant content, leaving 21 for full-text review. Upon further review, 15 more studies were excluded for the following reasons: six studies had duplicate data [18-23], one review [24], three studies with unavailable data [2527], and five observational studies [11, 28-31]. Six articles were included [32-37] (Fig. 1).

All of the studies included here were published between 2009 and 2015. Six studies comprising 309 patients were included in the meta-analysis. This included 156 patients with mesh and 153 patients without mesh. Study sample size ranged from 36 to 70 patients. Among these six studies, all reported the incidence of parastomal hernia, five reported stoma-related morbidity [32-34, 36, 37], and four reported reoperation related to parastomal hernia [33, 34, $36,37]$. There were three studies of sublay placement [32, $34,36]$ and three studies of intraperitoneal onlay mesh (IPOM) placement [33, 35, 37]. Synthetic mesh was used in the mesh group. Further characteristics of these studies are given in Tables 1 and 2 .

\section{Risk of bias and grades of evidence}

Allocation concealment was inadequate in all studies. Outcome assessment was blinded in two studies. The details for risk of bias are presented in Fig. 2. GRADE Working Group grades of evidence were moderate for the incidence of parastomal hernia, low for stoma-related morbidity, and moderate for reoperation related to parastomal hernia.

\section{Primary outcome: incidence of parastomal hernia}

All studies reported the incidence of parastomal hernia. The diagnosis of parastomal hernia was based solely on clinical examination in two studies $[32,36]$, solely on CT scans in one study [33], and on clinical examination and CT scans in two studies [34, 37]. One study did not disclose the diagnostic basis [35]. The incidences of parastomal hernia in the mesh group and non-mesh group were 24.4 and $50.3 \%$, respectively. The incidence of parastomal hernia was lower in the mesh group (RR, 0.42; $95 \% \mathrm{CI}$ 0.22-0.82, Fig. 3), and significant heterogeneity was observed among the studies $\left(P=0.004, I^{2}=71 \%\right)$.

\section{Sensitivity analysis}

Significant heterogeneity was observed across all trials in the primary outcome $\left(P=0.004, I^{2}=71 \%\right)$. As shown in Fig. 3, the results of the study conducted by Vierimaa et al. [37] were outside of the range of the others and probably contributed to the heterogeneity. After excluding this study, the results showed the mesh group to have a lower incidence of parastomal hernia than the non-mesh group (RR, 0.34; $95 \%$ CI 0.18-0.64). No significant heterogeneity was observed among the remaining studies $\left(P=0.11, I^{2}=47 \%\right)$.

\section{Subgroup analysis}

There was no significant difference between studies of sublay placement (three trials, RR, 0.25; $95 \%$ CI 0.08-0.80) and studies of IPOM placement (three trials, RR, 0.57; $95 \%$ CI $0.27-1.21)$ by the test of interaction $\left(P=0.24, I^{2}=28.9 \%\right)$. 
Table 1 Details of the articles included

\begin{tabular}{|c|c|c|c|c|c|c|c|}
\hline Reference & Year & Country & Journal & Type of mesh & $\begin{array}{l}\text { Position of } \\
\text { mesh } \\
\text { placement }\end{array}$ & $\begin{array}{l}\text { Location of } \\
\text { stoma }\end{array}$ & $\begin{array}{l}\text { Diagnostic bases } \\
\text { on parastomal } \\
\text { hernia }\end{array}$ \\
\hline $\begin{array}{l}\text { Lambrecht } \\
\text { et al. [32] }\end{array}$ & 2015 & Norway & $\begin{array}{l}\text { Colorectal } \\
\text { Dis }\end{array}$ & $\begin{array}{l}\text { Large-pore, low-weight polypropylene } \\
\text { mesh }\end{array}$ & Sublay & $\begin{array}{l}\text { Through the } \\
\text { rectus } \\
\text { abdominis } \\
\text { muscle }\end{array}$ & $\begin{array}{l}\text { Clinical } \\
\text { examination }\end{array}$ \\
\hline $\begin{array}{r}\text { Lopez-Cano } \\
\text { et al. [33] }\end{array}$ & 2012 & Spain & Hernia & $\begin{array}{l}\text { Large-pore lightweight mesh made of } \\
\text { polypropylene encapsulated with } \\
\text { polydioxanone }\end{array}$ & IPOM & $\begin{array}{l}\text { Through the } \\
\text { rectus } \\
\text { abdominis } \\
\text { muscle }\end{array}$ & CT scan \\
\hline $\begin{array}{r}\text { Serra-Aracil } \\
\text { et al. [34] }\end{array}$ & 2009 & Spain & Ann Surg & Ultrapro lightweight mesh & Sublay & $\begin{array}{l}\text { Through the } \\
\text { rectus } \\
\text { abdominis } \\
\text { muscle }\end{array}$ & $\begin{array}{l}\text { Clinical } \\
\text { examination } \\
\text { and CT scan }\end{array}$ \\
\hline $\begin{array}{r}\text { Serra-Aracil } \\
\text { et al. [35] }\end{array}$ & 2015 & Spain & $\begin{array}{l}\text { Dis Colon } \\
\text { Rectum }\end{array}$ & Large-pore lightweight composite mesh & IPOM & None & None \\
\hline $\begin{array}{l}\text { Tarcoveanu } \\
\text { et al. [36] }\end{array}$ & 2014 & Romania & Chirurgia & Polypropylene mesh & Sublay & $\begin{array}{l}\text { Through the } \\
\text { rectus } \\
\text { abdominis } \\
\text { muscle }\end{array}$ & $\begin{array}{l}\text { Clinical } \\
\quad \text { examination }\end{array}$ \\
\hline $\begin{array}{l}\text { Vierimaa } \\
\text { et al. [37] }\end{array}$ & 2015 & Finland & $\begin{array}{l}\text { Dis Colon } \\
\text { Rectum }\end{array}$ & $\begin{array}{l}\text { Dual-component structure composed of } \\
\text { polyvinylidene fluoride and } \\
\text { polypropylene }\end{array}$ & IPOM & $\begin{array}{l}\text { Through the } \\
\text { rectus } \\
\text { abdominis } \\
\text { muscle }\end{array}$ & $\begin{array}{l}\text { Clinical } \\
\text { examination } \\
\text { and CT scan }\end{array}$ \\
\hline
\end{tabular}

Sublay denotes either behind the rectus muscle above the posterior rectus sheath or between posterior sheath and peritoneum

IPOM denotes intraperitoneal onlay mesh implantation and direct contact between mesh and abdominal viscera

Table 2 Characteristics of the included articles

\begin{tabular}{|c|c|c|c|c|c|c|}
\hline Reference & Approach & Sample size & $\begin{array}{l}\text { Age (year) } \\
\text { mean } \pm \mathrm{SD}\end{array}$ & Female N (\%) & $\begin{array}{l}\mathrm{BMI}\left(\mathrm{kg} / \mathrm{m}^{2}\right) \\
\text { mean } \pm \mathrm{SD}\end{array}$ & $\begin{array}{l}\text { Follow-up duration, months } \\
\text { median }\end{array}$ \\
\hline \multirow[t]{2}{*}{ Lambrecht et al. [32] } & Mesh & 32 & $64 \pm 4.0$ & $10(31.3)$ & $24.6 \pm 0.6$ & 36 \\
\hline & Non-mesh & 26 & $63 \pm 4.1$ & $5(19.2)$ & $25.5 \pm 0.8$ & 48 \\
\hline \multirow[t]{2}{*}{ Lopez-Cano et al. [33] } & Mesh & 19 & $72.2 \pm 7.6$ & $8(42.1)$ & $26.3 \pm 3.2$ & 10.6 \\
\hline & Non-mesh & 17 & $65.9 \pm 13.9$ & $10(58.8)$ & $27.5 \pm 4.7$ & 10.6 \\
\hline \multirow[t]{2}{*}{ Serra-Aracil et al. [34] } & Mesh & 27 & $67.5 \pm 8.8$ & $5(18.5)$ & $25.6 \pm 2.9$ & 29 \\
\hline & Non-mesh & 27 & $67.2 \pm 9.7$ & $8(29.6)$ & $27.3 \pm 3.5$ & 29 \\
\hline \multirow[t]{2}{*}{ Serra-Aracil et al. [35] } & Mesh & 23 & & & & 18 \\
\hline & Non-mesh & 26 & & & & 18 \\
\hline \multirow[t]{2}{*}{ Tarcoveanu et al. [36] } & Mesh & 20 & & & & 20 \\
\hline & Non-mesh & 22 & & & & 20 \\
\hline \multirow[t]{2}{*}{ Vierimaa et al. [37] } & Mesh & 35 & $67.1 \pm 10.7$ & $17(48.6)$ & $26.2 \pm 4.6$ & 12 \\
\hline & Non-mesh & 35 & $65.1 \pm 11.7$ & $16(45.7)$ & $25.4 \pm 4.3$ & 12 \\
\hline
\end{tabular}

$S D$ Standard deviation, $B M I$ body mass index

\section{Effect of missing data}

Of the six included studies, two did not report the number of deaths and missing visits [35, 36], two studies used intention-to-treat analysis [34, 37], and the remaining studies reported the number of deaths and missed visits but did not use intention-to-treat analysis [32, 33]. Assuming that eleven people who died in the mesh group developed a parastomal hernia, the incidence of parastomal hernia remained lower in the mesh group $(31.4 \%)$ than in the non-mesh group $(50.3 \%)$ (RR, $0.61 ; 95 \%$ CI 0.39-0.96; $P=0.03)$. 
Fig. 2 Assessment for risk of bias

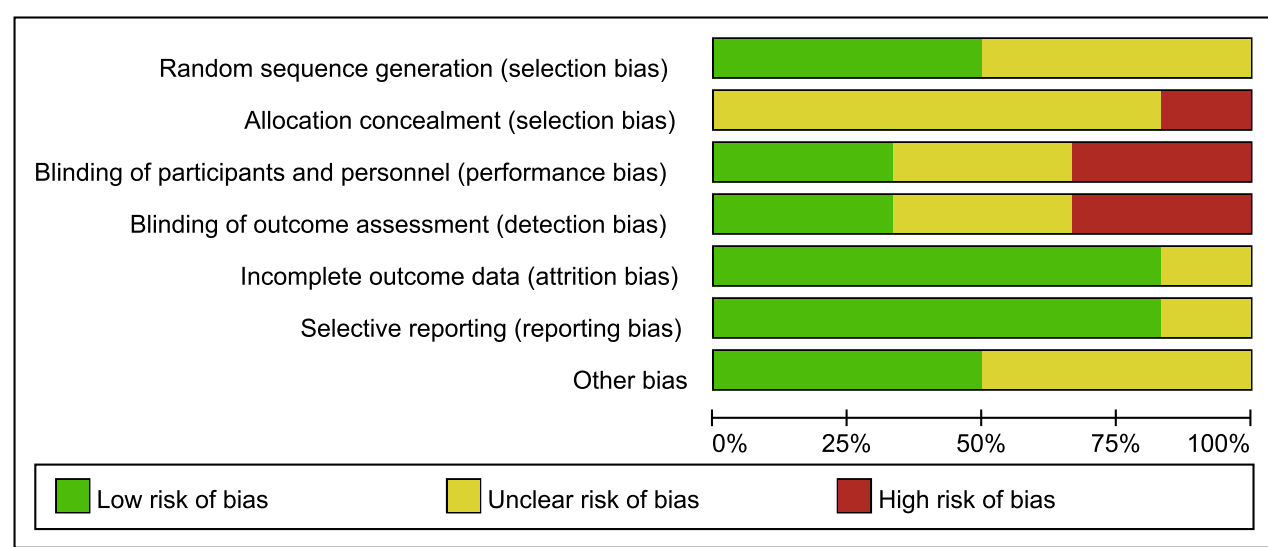

\begin{tabular}{|c|c|c|c|c|c|c|}
\hline 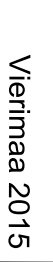 & 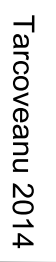 & 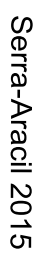 & 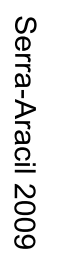 & 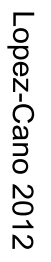 & 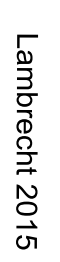 & \\
\hline+ & $\sim$ & $\cdot$ & 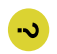 & + & + & Random sequence generation (selection bias) \\
\hline$\sim$ & $v$ & $\cdot$ & 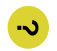 & $\Omega$ & $\cdot$ & Allocation concealment (selection bias) \\
\hline & $\nu$ & $\sim$ & + & + & (1) & Blinding of participants and personnel (performance bias) \\
\hline & $v$ & $\sim$ & + & + & . & Blinding of outcome assessment (detection bias) \\
\hline+ & + & $\cdot$ & + & + & + & Incomplete outcome data (attrition bias) \\
\hline+ & + & $\sim$ & + & + & + & Selective reporting (reporting bias) \\
\hline+ & $\sim$ & $\sim$ & + & + & 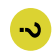 & Other bias \\
\hline
\end{tabular}

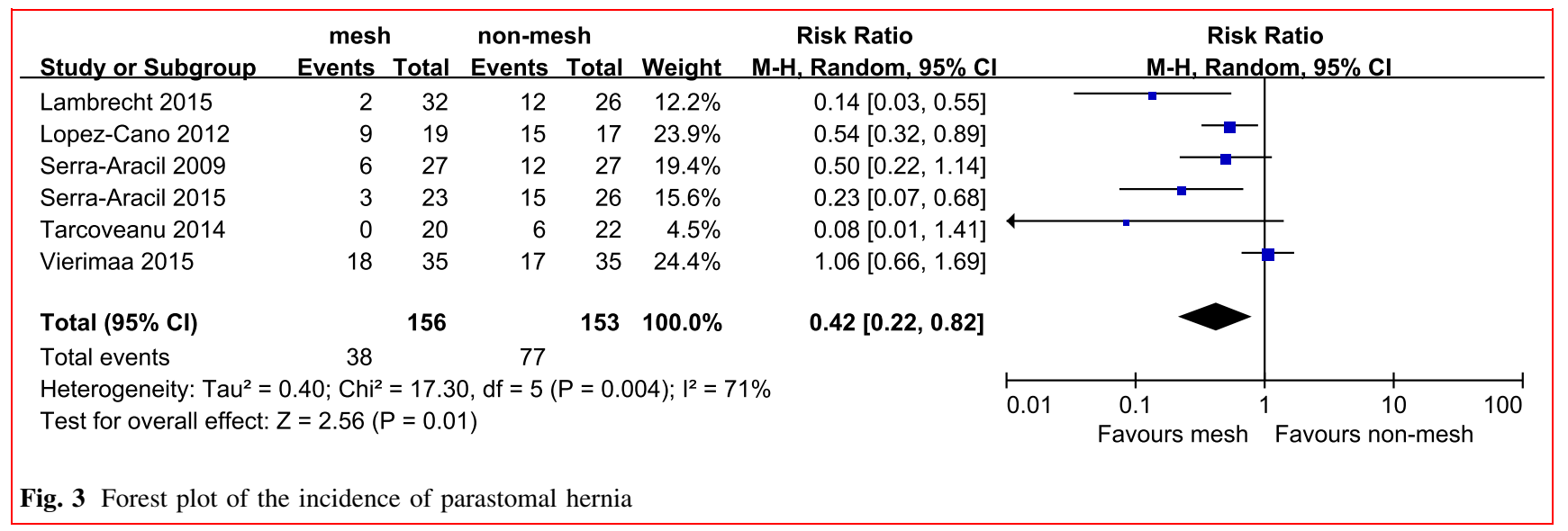




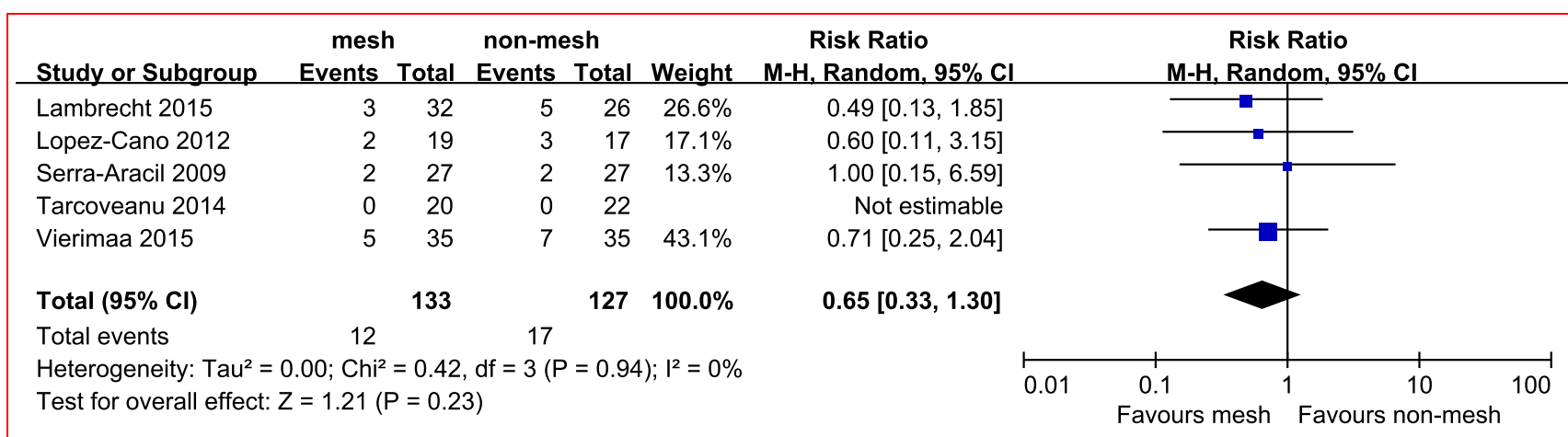

Fig. 4 Forest plot of stoma-related morbidity

\section{Secondary outcomes}

Five studies reported stoma-related morbidity and there was no heterogeneity among them $\left(P=0.94, I^{2}=0 \%\right)$. In the random effects model, stoma-related morbidity was similar between the mesh and non-mesh groups (RR, 0.65; $95 \%$ CI 0.33-1.30) (Fig. 4).

Four studies reported, reoperation related to parastomal hernia. The pooled results from these studies showed the mesh group to be associated with a lower risk of reoperation related to parastomal hernia (RR, 0.23; $95 \% \mathrm{CI}$ 0.06-0.89, Fig. 5), with no heterogeneity among the studies $\left(P=0.96, I^{2}=0 \%\right)$.

\section{Publication bias}

Assessment of publication bias showed that there was no potential publication bias among the included studies (Begg's test, $P=0.13$ ).

\section{Discussion}

Our study evaluated efficacy of prophylactic mesh at end-colostomy construction. The results revealed that, for sigmoid end-colostomy, prophylactic placement of a mesh reduced the incidence of parastomal hernia, reoperation related to parastomal hernia, and made no significant difference in terms of stoma-related morbidity.

These results were similar to those published in a previous meta-analysis by Wijeyekoon et al. [38]. However, the selection of the study population was different between these two studies. The prior study included all patients with end and loop stomas. Because the incidence of parastomal hernia was different between end and loop stomas [39, 40], the present study only included those patients who underwent permanent end-colostomy surgery to treat cancer of the rectum. The prior analysis only included three articles involving a total of 129 patients. The present meta-analysis included more recently published articles and a greater number of patients than Wijeyekoon et al. did; therefore, it was more likely to detect differences.

Parastomal hernia is caused by enlargement of the trephine opening in the abdominal wall, which is usually due to the working of mechanical tangential stress on the circumference of the opening. Reinforcing the abdominal wall with mesh during the initial operation might reduce the incidence of parastomal hernia. The mesh group was found to have a distinct advantage over the non-mesh group with respect to the incidence of the parastomal hernia. In the studies included here, mesh was placed as a sublay or in the intraperitoneal plane. The sublay technique is considered feasible and can lower the incidence of parastomal hernia

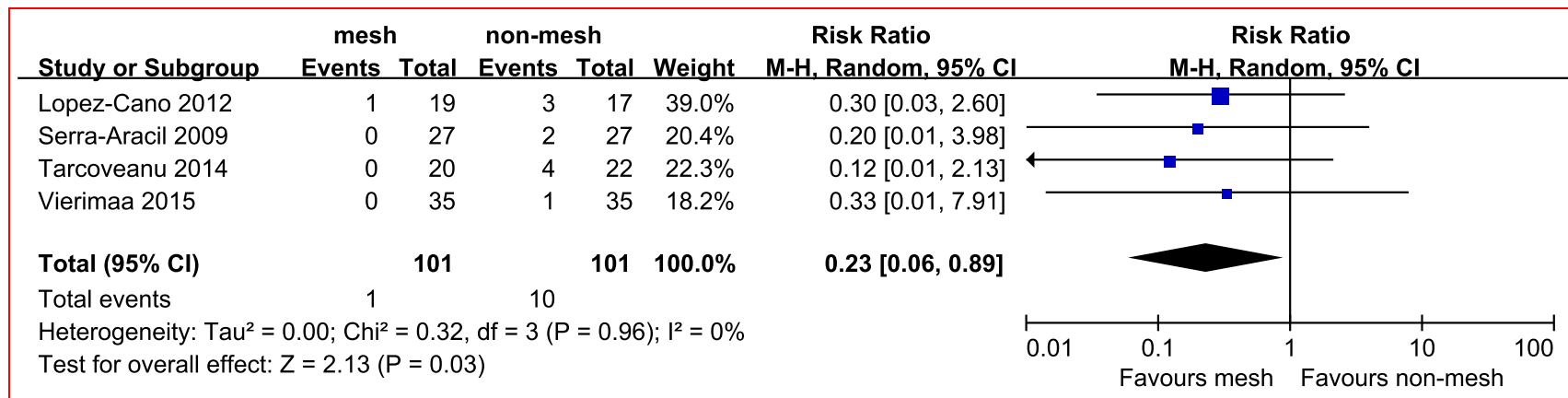

Fig. 5 Forest plot of reoperation related to parastomal hernia 
[10]. The intraperitoneal technique includes the modified Sugarbaker method, the keyhole technique, and the sandwich technique. The keyhole technique involves cutting a hole in the mesh to destroy its architecture and reduce its tensile strength, resulting in gradual widening of the opening. The modified Sugarbaker technique is believed to be superior to the keyhole technique because it is associated with fewer recurrences [41, 42]. Although the keyhole technique was used on more patients than the modified Sugarbaker technique in the included studies, the incidence of parastomal hernia was lower in mesh group than that in non-mesh group.

What concerns surgeons is the risk of complications attributable to insertion of a prosthetic material into a potentially contaminated field such as an open bowel. They are particularly concerned about the risk of wound infection, which may necessitate mesh removal. The intraperitoneal technique is an aseptic procedure involving no contact between the mesh and the broken ends of the transected colon. The sigmoid colon used to create the stoma is passed through the abdominal wall before the mesh is placed. In this meta-analysis, there were no cases of mesh removal for the reason of infection in cases treated with the sublay technique. This may be because of the lower rate of inflammatory reaction and better defense against infection with large-pore lightweight mesh [43]. After preparation of the bowel and the management of pollution, mesh can be used in the presence of open bowel with minimal risk of infection [44, 45]. Although Aldridge [46] reported a case of erosion and perforation of colon by synthetic mesh, this complication is rare, and improvements to materials and techniques have made it rarer. In the studies examined here, stoma detachment and necrosis of the colostomy were more common than erosion or perforation, and it was not the mesh but the blood supply and tension of sigmoid colon that cause these complications. In this way, no significant differences in stoma-related complications were found between the two groups.

Analysis showed the mesh group to have advantages not only related to the incidence of the parastomal hernia but also related to reoperation for parastomal hernia. The significant increases in aperture size were observed in the nonmesh group after CT scan [32], which can cause discomfort, may go some way toward explaining this.

Even though the results are encouraging, there are still factors that must be considered. Some of the patients in the mesh group died from recurrence of cancer within 12 months. Even when it was assumed that everyone in the mesh group who died had developed a parastomal hernia, the results of the meta-analysis did not change. It is not appropriate to place a mesh in patients whose survival time is less than 1 year. Once these patients are excluded, prophylactic mesh placement can be considered cost-effective.
The incremental cost-effectiveness ratio (ICER) was \$6676/QALY (quality adjusted life years) [47]. Several studies have found female gender, higher body mass index, and lower levels of preoperative albumin to offer significant independent risk for parastomal hernia [48, 49]. However, none of the studies evaluated the placement of mesh in these specific patients. This may be a suitable subject for future studies.

This study has a number of limitations that should be considered. First, there are different protocols for diagnosis of parastomal hernia. Parastomal hernia, whether diagnosed by clinical examination or by $\mathrm{CT}$ scan, has no consistent definition. Clinical examination is a subjective method, and it can be especially difficult to identify parastomal hernia in obese patients. Although CT scanning is an objective method, it is subject to false negatives. A definition of parastomal hernia for use with clinical examination that matches findings from $\mathrm{CT}$ scans should be established [50]. Second, the follow-up period was different in different studies, though it was more than 12 months in most of them. Although most cases of parastomal hernia appear within the first 12 months of construction, a higher incidence of parastomal hernia is reported with longer follow-up [19, 25]. Future trials should have follow-up times of 12 months or longer. Finally, although we included RCT, some of the following factors might still produce a biased estimate of the effects of treatment effect. Random sequence generation was adequate in only three of the studies included here. Only one study provided sufficient information to assess allocation concealment, and it did so inadequately. Blinding of outcome assessment was used in two of the included studies.

In conclusion, available evidence suggests that prophylactic mesh at end-colostomy construction after surgery for low rectal cancer is an effective and safe procedure. However, the results should be interpreted with caution because of the heterogeneity among the studies and prophylactic mesh placement in all patients or in patients with specific needs requires further study.

Acknowledgments The authors thank LetPub (www.letpub.com) for its linguistic assistance during the preparation of this manuscript.

\section{Compliance with ethical standards}

Conflict of interest The authors have declared that no competing interests exist.

Open Access This article is distributed under the terms of the Creative Commons Attribution 4.0 International License (http://creative commons.org/licenses/by/4.0/), which permits unrestricted use, distribution, and reproduction in any medium, provided you give appropriate credit to the original author(s) and the source, provide a link to the Creative Commons license, and indicate if changes were made. 


\section{References}

1. Ferlay J, Soerjomataram I, Dikshit R et al (2015) Cancer incidence and mortality worldwide: sources, methods and major patterns in GLOBOCAN 2012. Int J Cancer 136:E359-E386

2. Hamada M, Tamura T, Sakamoto S et al (2013) Laparoscopic treatment of parastomal hernia using sugerbaker technique with parietex composite mesh. Surg Endosc Other Interv Tech 27:S389

3. Hotouras A, Thaha MA, Power N et al (2011) Preventing parastomal hernias: How critical is the trephine size? Colorectal Dis $13: 45$

4. Kald A, Juul KN, Hjortsvang $\mathrm{H}$ et al (2008) Quality of life is impaired in patients with peristomal bulging of a sigmoid colostomy. Scand J Gastroenterol 43:627-633

5. van Dijk SM, Timmermans L, Deerenberg EB et al (2015) Parastomal hernia: impact on quality of life? World J Surg 39:2595-2601

6. DeAsis FJ, Linn JG, Lapin B et al (2015) Modified laparoscopic Sugarbaker repair decreases recurrence rates of parastomal hernia. Surgery 158:954-961

7. Ripoche J, Basurko C, Fabbro-Perray P et al (2011) Parastomal hernia. A study of the French federation of ostomy patients. J Visc Surg 148:e435-e441

8. Hansson BM, de Hingh IH, Bleichrodt RP (2007) Laparoscopic parastomal hernia repair is feasible and safe: early results of a prospective clinical study including 55 consecutive patients. Surg Endosc 21:989-993

9. Mancini GJ, McClusky DA 3rd, Khaitan L et al (2007) Laparoscopic parastomal hernia repair using a nonslit mesh technique. Surg Endosc 21:1487-1491

10. Valdes-Hernandez J, Milanes JAD, Morales LCC (2015) Prevention of parastomal hernia with a preperitoneal polypropelene mesh. Cir Esp 93:455-459

11. Nikberg M, Sverrisson I, Tsimogiannis K et al (2015) Prophylactic stoma mesh did not prevent parastomal hernias. Int $\mathbf{J}$ Colorectal Dis 30:1217-1222

12. Moher D, Liberati A, Tetzlaff J et al (2009) Preferred reporting items for systematic reviews and meta-analyses: the PRISMA statement. PLoS Med 6:e1000097

13. Moreno-Matias J, Serra-Aracil X, Darnell-Martin A et al (2009) The prevalence of parastomal hernia after formation of an end colostomy. A new clinico-radiological classification. Colorectal Dis 11:173-177

14. Higgins JP, Altman DG, Gotzsche PC et al (2011) The Cochrane Collaboration's tool for assessing risk of bias in randomised trials. BMJ 343:d5928

15. Guyatt GH, Oxman AD, Vist GE et al (2008) GRADE: an emerging consensus on rating quality of evidence and strength of recommendations. BMJ 336:924-926

16. Altman DG, Bland JM (2003) Interaction revisited: the difference between two estimates. BMJ 326:219

17. Begg CB, Mazumdar M (1994) Operating characteristics of a rank correlation test for publication bias. Biometrics 50:1088-1101

18. Janes A, Cengiz Y, Israelsson LA (2004) Preventing parastomal hernia with a prosthetic mesh. Arch Surg 139(1356-135):8

19. Janes A, Cengiz Y, Israelsson LA (2004) Randomized clinical trial of the use of a prosthetic mesh to prevent parastomal hernia. Br J Surg 91(280-28):2

20. Serra-Aracil X, Bombardo-Junca J, Moreno-Matias J (2009) Randomized, controlled, prospective trial of the use of mesh to prevent parastomal hernia. Dis Colon Rectum 52:1676
21. Smart N, Massey L, Boone D et al (2013) Does prophylactic intraperitoneal biologic mesh placement prevent paracolostomy hernias? Dis Colon Rectum 56:e180-e181

22. Tsimogiannis K, Sverrisson I, Smedh K et al (2014) Prophylactic stoma mesh placement did not prevent parastomal hernias. Colorectal Dis 16:35

23. Ventham N, Brady R, Stewart R et al (2011) Prophylatic mesh plication of permanent stomas at index laparotomy for colorectal cancer; radiological outcomes and complications. Colorectal Dis 13:10

24. Schafer M (2009) Preventing parastomal hernia with a prosthetic mesh: a five year follow up of a randomised study. World J Surg 33:122-123

25. Janes A, Cengiz Y, Israelsson LA (2009) Preventing parastomal hernia with a prosthetic mesh: a 5-year follow-up of a randomized study. World J Surg 33:118-121 (discussion 122-113)

26. Fleshman J, Wexner S, Ellis C et al (2011) Safety and early quality of life after Strattice ${ }^{\mathrm{TM}}$ tissue matrix placement at the time of stoma construction: a randomized, controlled trial. Dis Colon Rectum 54:e80

27. Fleshman JW, Beck DE, Hyman N et al (2014) A prospective, multicenter, randomized, controlled study of non-cross-linked porcine acellular dermal matrix fascial sublay for parastomal reinforcement in patients undergoing surgery for permanent abdominal wall ostomies. Dis Colon Rectum 57:623-631

28. Ventham NT, Brady RR, Stewart RG et al (2012) Prophylactic mesh placement of permanent stomas at index operation for colorectal cancer. Ann R Coll Surg Engl 94(569-57):3

29. Jánó Z, Nagy A (2014) Results of 3-dimensional mesh implantations at the time of Miles operation to prevent parastomal hernia. Eur Surg Acta Chir Austriaca 46:25-31

30. Li Y, Chen Z, Ye J et al (2015) Preventing parastomal hernia with prophylactic use of dual-mesh in patients with colostomy. Eur Surg Acta Chir Austriaca 47:S213-S214

31. Massey L, Smart N, Boone D et al (2013) Does prophylactic intraperitoneal cross-linked biologic mesh placement prevent the formation of paracolostomy hernias after laparoscopic abdominoperineal excision for low rectal cancer? Colorectal Dis 15:48

32. Lambrecht JR, Larsen SG, Reiertsen O et al (2015) Prophylactic mesh at end-colostomy construction reduces parastomal hernia rate: a randomized trial. Colorectal Dis 17(O191-19):7

33. Lopez-Cano M, Lozoya-Trujillo R, Quiroga S et al (2012) Use of a prosthetic mesh to prevent parastomal hernia during laparoscopic abdominoperineal resection: a randomized controlled trial. Hernia 16:661-667

34. Serra-Aracil X, Bombardo-Junca J, Moreno-Matias J et al (2009) Randomized, controlled, prospective trial of the use of a mesh to prevent parastomal hernia. Ann Surg 249:583-587

35. Serra-Aracil X, Lopez-Cano M, Mora L et al (2015) Parastomal hernia prevention through laparoscopic modified sugarbaker technique with composite mesh (Physiomesh ${ }^{\mathrm{TM}}$ ). A multicenter randomized controlled trial. Dis Colon Rectum 58:e110

36. Tarcoveanu E, Vasilescu A, Cotea E et al (2014) Parastomal hernias. Clin Study Ther Strateg Chir (Bucur) 109:179-184

37. Vierimaa M, Klintrup K, Biancari F et al (2015) Prospective, randomized study on the use of a prosthetic mesh for prevention of parastomal hernia of permanent colostomy. Dis Colon Rectum 58:943-949

38. Wijeyekoon SP, Gurusamy K, El-Gendy K et al (2010) Prevention of parastomal herniation with biologic/composite prosthetic mesh: a systematic review and meta-analysis of randomized controlled trials. J Am Coll Surg 211:637-645

39. Carne PW, Robertson GM, Frizelle FA (2003) Parastomal hernia. Br J Surg 90:784-793 
40. Pilgrim CH, McIntyre R, Bailey M (2010) Prospective audit of parastomal hernia: prevalence and associated comorbidities. Dis Colon Rectum 53:71-76

41. Hansson BM, Slater NJ, van der Velden AS et al (2012) Surgical techniques for parastomal hernia repair: a systematic review of the literature. Ann Surg 255:685-695

42. Muysoms EE, Hauters PJ, Van Nieuwenhove Y et al (2008) Laparoscopic repair of parastomal hernias: a multi-centre retrospective review and shift in technique. Acta Chir Belg 108:400-404

43. Jacob DA, Schug-Pass C, Sommerer F et al (2012) Comparison of a lightweight polypropylene mesh (Optilene(R) LP) and a large-pore knitted PTFE mesh (GORE(R) INFINIT(R) mesh) biocompatibility in a standardized endoscopic extraperitoneal hernia model. Langenbecks Arch Surg 397:283-289

44. Geisler DJ, Reilly JC, Vaughan SG et al (2003) Safety and outcome of use of nonabsorbable mesh for repair of fascial defects in the presence of open bowel. Dis Colon Rectum 46:1118-1123
45. Shi Y, Guo X, Zhuo H et al (2015) Application of synthetic mesh in contaminated ventral hernia repair. Eur Surg Acta Chir Austriaca 47:S217-S218

46. Aldridge AJ, Simson JN (2001) Erosion and perforation of colon by synthetic mesh in a recurrent paracolostomy hernia. Hernia 5:110-112

47. Fleming F, Kelly KN, Monson JR et al (2014) Prophylactic mesh placement in patients undergoing permanent colostomy formation is cost-effective. J Surg Res 186:533

48. Donahue TF, Bochner BH, Sfakianos JP et al (2014) Risk factors for the development of parastomal hernia after radical cystectomy. J Urol 191:1708-1713

49. Funahashi K, Suzuki T, Nagashima Y et al (2014) Risk factors for parastomal hernia in Japanese patients with permanent colostomy. Surg Today 44:1465-1469

50. Janes A, Weisby L, Israelsson LA (2011) Parastomal hernia: clinical and radiological definitions. Hernia 15:189-192 